\title{
Continuous flow enantioselective arylation of aldehydes with ArZnEt using triarylboroxins as the ultimate source of aryl groups
}

\author{
Julien Rolland ${ }^{1}$, Xacobe C. Cambeiro ${ }^{1}$, Carles Rodríguez-Escrich ${ }^{1}$ \\ and Miquel A. Pericàs ${ }^{*} 1,2$
}

\section{Full Research Paper}

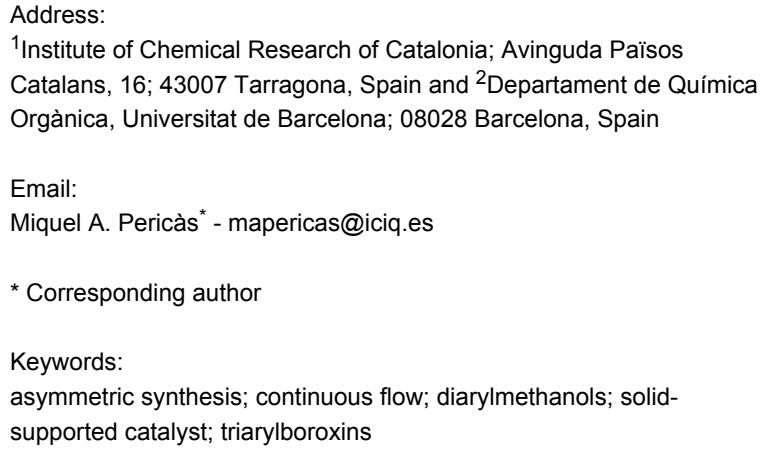

${ }^{1}$ Institute of Chemical Research of Catalonia; Avinguda Països Catalans, 16; 43007 Tarragona, Spain and ${ }^{2}$ Departament de Química Orgànica, Universitat de Barcelona; 08028 Barcelona, Spain

Beilstein Journal of Organic Chemistry 2009, 5, No. 56 doi:10.3762/bjoc.5.56

Received: 13 July 2009

Accepted: 02 October 2009

Published: 15 October 2009

Guest Editor: A. Kirschning

(c) 2009 Rolland et al; licensee Beilstein-Institut. License and terms: see end of document.

\section{Abstract}

A continuous flow system for the synthesis of enantioenriched diarylmethanols from aldehydes is described. The system uses an amino alcohol-functionalized polystyrene resin as the catalyst, and the arylating agent is conveniently prepared by transmetallation of triarylboroxins with diethylzinc.

\section{Introduction}

Diarylmethanols constitute the basic scaffold in several important drugs such as antihistamines and muscle relaxants $(R)$-neobenodine, $(R)$-orphenadrine or $(S)$-carbinoxamine (Figure 1) [1]. Despite the apparent simplicity of the structures, their asymmetric synthesis is not trivial. For instance, access to these structures through enantioselective reduction of the corresponding ketones can become troublesome when both aryl groups are similar in their electronic and steric properties [2-4].

On the other hand, enantioselective arylation of aldehydes with organozinc reagents appears as a most convenient alternative,

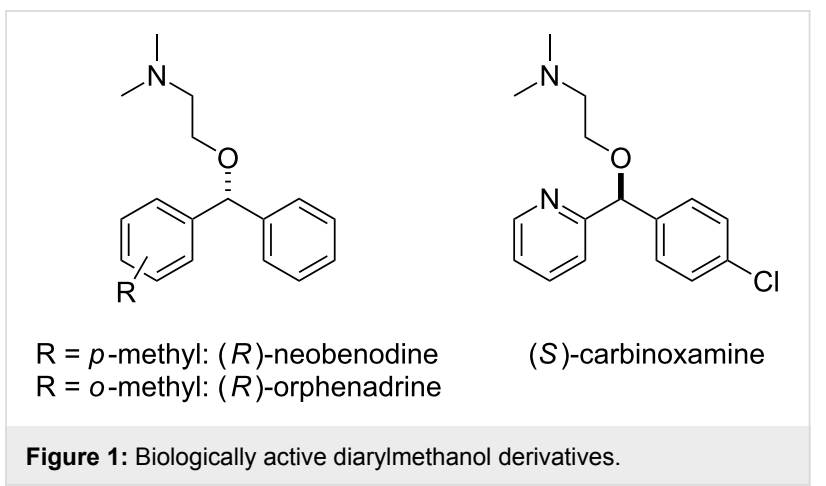


since the initial aldehyde undergoing addition presents two very different groups (namely, a $\mathrm{H}$ atom and an aryl group) and hence offers good opportunities for enantiocontrol [5-7].

Whereas the catalytic enantioselective addition of diethylzinc to aldehydes has been thoroughly studied, progress in the control of the analogous asymmetric arylation has been hampered by the fact that $\mathrm{Ar}_{2} \mathrm{Zn}$ species are several orders of magnitude more active than their dialkyl counterparts [8]. In this way, when diphenylzinc has been used as the arylating species in these processes, the background, non catalyzed reaction gives rise to a racemic product, which significantly erodes the global enantioselectivity of the reactions $[6,9]$.

The most successful approach to overcome this difficulty comes from the Bolm laboratory and has been based on the use of the comparatively less reactive mixed species PhEtZn, easily prepared from a mixture of $\mathrm{Ph}_{2} \mathrm{Zn}$ and $\mathrm{Et}_{2} \mathrm{Zn}$ [10-13]. With this strategy, it has become possible to achieve good levels of enantioselectivity in the arylation reaction, although usually at the cost of low catalytic activity, high catalytic loadings being required for the achievement of satisfactory yields $[14,15]$. In contrast, $\beta$-amino alcohol 1 (Figure 2), developed in our laboratory [16], showed high activity and enantioselectivity in the ethylation [16], methylation [17], and arylation [18] of a wide family of substrates at low catalyst loadings.<smiles>OC(c1ccccc1)(c1ccccc1)C(c1ccccc1)N1CCCCC1</smiles>

1

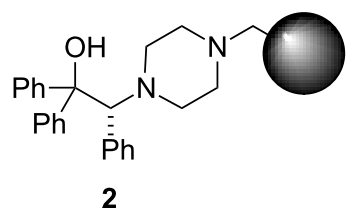

2
Figure 2: Structures of (R)-1,1,2-triphenyl-2-(piperidin-1-yl)ethanol (1) and its polystyrene-immobilized analogue 2 .

In recent times, we have developed strategies for the immobilization of analogues of $\mathbf{1}$ onto solid supports [19-22]. Among the ligands resulting from these studies, the polystyrene-supported catalyst $\mathbf{2}$ displayed levels of catalytic activity and selectivity comparable to those of the homogeneous model $\mathbf{1}$. Noteworthy, this catalytic resin has allowed the development of the first catalytic enantioselective arylation of aldehydes employing an insoluble catalyst [22], and has been used as the basis for a single-pass, continuous flow highly enantioselective ethylation of aldehydes characterized by very short residence times (down to $2.8 \mathrm{~min}$ ) [23]. According to these precedents, we considered that 2 could be a good candidate for a planned continuous enantioselective production of diarylmethanols.
When a large scale production of diarylmethanols involving the enantioselective transfer of aryl groups from zinc to aldehydes is considered, the cost of the arylating agent becomes an important issue. From this perspective, substantial efforts have been devoted to improve the economy of this process, by replacing the expensive $\mathrm{Ph}_{2} \mathrm{Zn}$ by other, more convenient, aryl sources.

To this end, the use of arylboron species has provided particularly good results. In contrast to what happens with diarylzinc reagents, a wide variety of arylboronic acids are commercially available at a convenient price, and these species have been explored as the ultimate source of aryl groups [24-29]. In these approaches generally good results have been obtained, but at the expense of using a large excess of diethylzinc for the transmetallation step, since two non-productive equivalents of the reagent are consumed in the initial reaction with the boronic acid (Scheme 1).

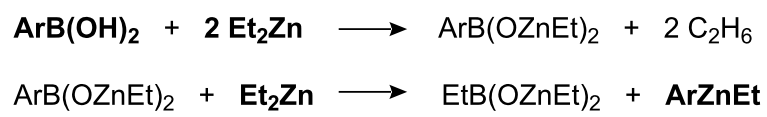

Scheme 1: Generation of the mixed ArZnEt species from a boronic acid and $\mathrm{Et}_{2} \mathrm{Zn}$.

On the other hand, triarylboroxins, easily prepared from the corresponding arylboronic acids by thermally induced dehydration under vacuum, have recently been applied with success as the starting materials for the preparation of the ArZnEt species to be used in the reaction [30-32] (Scheme 2). This represents a highly atom-economical approach since, in principle, no sacrificial excess of diethylzinc is needed for the transmetallation process and up to a $74 \%$ of the molecular mass of triphenylboroxin (the less favourable example) can be transferred to the reacting carbonyl compound.

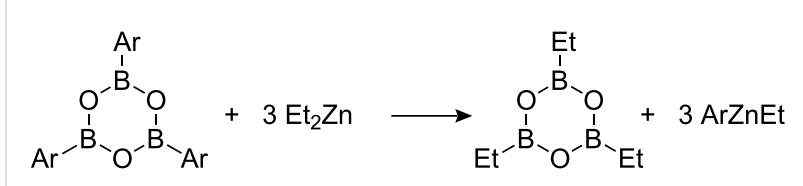

Scheme 2: Generation of the mixed ArZnEt species from a triarylboroxin and $\mathrm{Et}_{2} \mathrm{Zn}$.

It is to be mentioned that other strategies for the preparation of mixed alkylarylzinc species from cheap organometallic reagents have been developed in recent times and could probably be also used for the same purpose [33-35]. 
Flow chemistry [36-39] is increasingly seen as a promising methodology for the clean and economic production of complex substances. According to this, the field is experiencing a fast growth both in methodological aspects [40-43] and in applications [44-51]. In any case, examples of continuous flow enantioselective processes [52] are still scarce [22,53-57] in spite of the enormous potential of this methodology. Herein, we report the development of a continuous flow system for the preparation of enantioenriched diarylmethanols using triarylboroxins as the ultimate aryl group source.

\section{Results and Discussion Preparation of the immobilized catalyst}

Resin 2 was prepared in three steps from commercially available triphenylethylene according to a reported procedure [21]. In the key steps, enantiomerically pure triphenylethylene oxide [58] is submitted to regioselective and stereospecific ringopening with piperazine, and the resulting diamino alcohol $\mathbf{3}$ is subsequently supported onto a slightly cross-linked (1\% DVB) Merrifield resin by direct treatment at room temperature in DMF in the presence of cesium carbonate (Scheme 3 ).

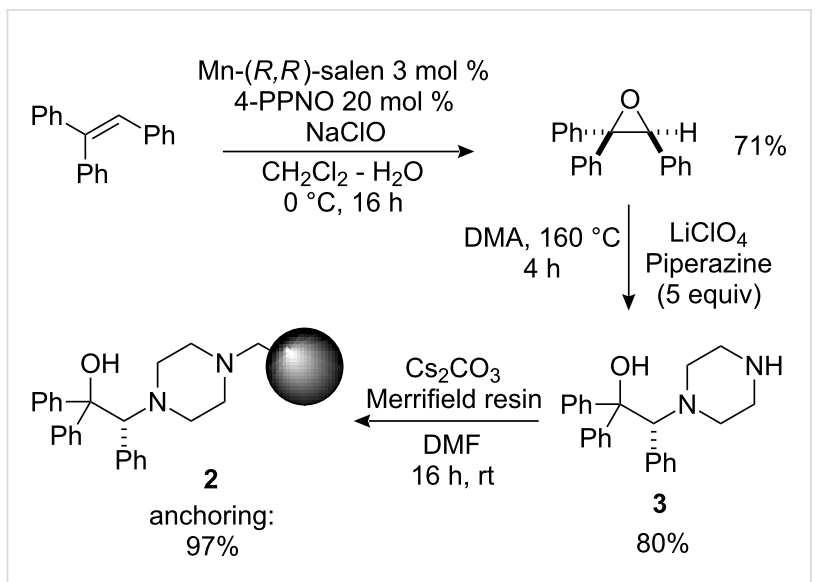

Scheme 3: Synthesis of the immobilized amino alcohol 2.

\section{Evaluation of resin $\mathbf{2}$ under batch conditions}

Prior to the continuous flow experiments, resin 2 was tested under batch conditions as a catalyst for the enantioselective phenylation of tolualdehyde using triphenylboroxin as the phenyl source (Scheme 4). In these studies, emphasis was put on the determination on the minimal ratio between triphenylboroxin and diethylzinc able to suppress competing ethyl transfer processes, and on the minimal amount of arylating species leading to complete conversion of the starting aldehyde.

Employing with 2 the reaction conditions previously optimized for the homogeneous ligand $\mathbf{1}$ [30], the addition product was obtained in slightly lower yield and enantioselectivity (entry 1 ,

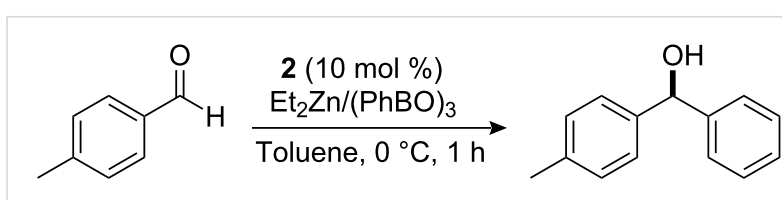

Scheme 4: Phenylation of tolualdehyde catalyzed by 2 .

Table 1). This is probably due to the fact that the triethylboroxin co-product can trigger a non-enantioselective pathway for the arylation reaction; in fact, a decrease in the amount of $(\mathrm{PhBO})_{3}$, as well as an increase in the amount of $\mathrm{ZnEt}_{2}$ employed for the transmetallation, allowed us to obtain the product in a somewhat better $e e$, although at the expense of a lower yield (entries 2 and 4). In the optimal conditions, when 2.5 equiv of $\mathrm{ZnEt}_{2}$ and 0.4 equiv of $(\mathrm{PhBO})_{3}$ were used (entry 3), the diarylmethanol product was obtained in $73 \%$ yield and $89 \%$ ee.

Table 1: Optimization of batch conditions for the phenylation of tolual-
dehyde with triphenylboroxin with $\mathbf{2}$ as the catalyst. ${ }^{a}$
\begin{tabular}{lllll} 
Entry & $\begin{array}{l}\text { (PhBO) } \\
\text { (equiv) }\end{array}$ & $\begin{array}{l}\text { ZnEt }_{2} \\
\text { (equiv) }\end{array}$ & Yield (\%) & ee (\%) \\
\hline 1 & 0.6 & 2.4 & 90 & 83 \\
2 & 0.4 & 2.0 & 62 & 85 \\
3 & 0.4 & 2.5 & 73 & 89 \\
4 & 0.4 & 3.0 & 72 & 88 \\
\hline
\end{tabular}

aAll reactions run at $0{ }^{\circ} \mathrm{C}$ for $1 \mathrm{~h}$ at $0.2 \mathrm{M}$ concentration of tolualdehyde.

\section{Continuous flow system \\ System set-up}

For the continuous flow experiments, a system similar to that previously described for the enantioselective ethylation of aldehydes [23] was used (Figure 3). The flow reactor consists of a vertically mounted, fritted and jacketed low-pressure chromatography Omnifit glass column $(10 \mathrm{~mm}$ bore size and a $70 \mathrm{~mm}$ maximal bed height) completely filled with the swollen resin. During operation, the reagents were pumped in through the bottom end of the column using two different piston pumps (one for the aldehyde substrate in toluene and one for the PhZnEt plus triethylboroxin mixture in toluene). Both flows were mixed in a $\mathrm{T}$-shaped piece placed immediately before the reactor, in order to minimize the amount of background, nonenantioselective addition reaction before contact with the supported catalyst. Additionally, a supply of dry toluene was connected to both pumps, for swelling the resin and washing the tubing before and after the reaction. Isothermal operation was secured by circulation of a cooling fluid at the desired operation temperature through the column jacket. Finally, a collecting flask containing ammonium chloride solution was set in order 


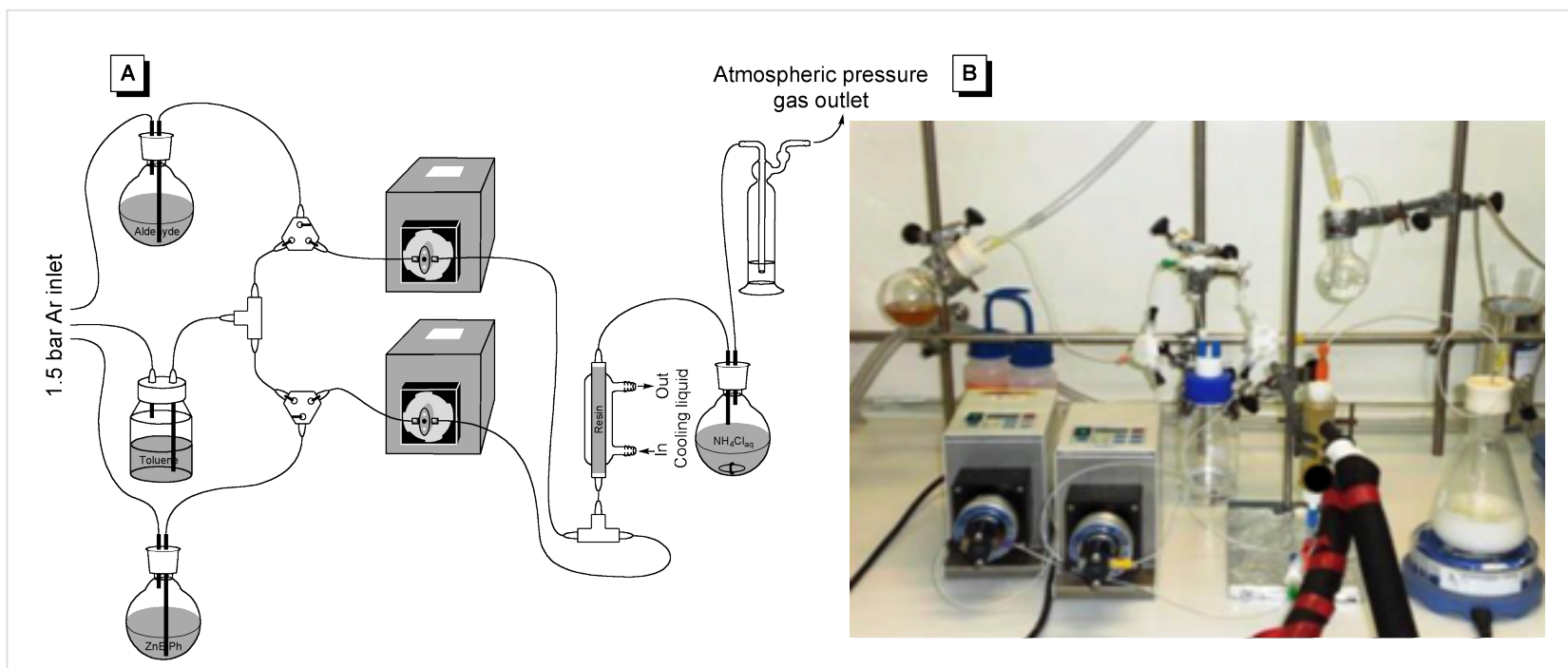

Figure 3: Experimental set-up for the continuous flow experiments. (A) Schematic representation and (B) Actual system.

to hydrolyze residual ethylating/arylating agents and thus prevent the non catalyzed reaction taking place in the event that conversion of the continuous flow catalytic reaction was not complete.

\section{Optimization of the process}

Optimization of reaction parameters under continuous flow conditions was performed again on the phenylation reaction of $p$-tolualdehyde. The results of this study are summarized in Table 2. Bearing in mind the strong acceleration usually observed when reactions are run under continuous flow conditions, due to the higher effective concentration of the catalyst, the use of a smaller excess of diethylzinc than under batch conditions was initially tested at $0{ }^{\circ} \mathrm{C}$ (entry 1 ). However, this resulted in low levels of conversion and enantioselectivity. As already observed under batch conditions, the use of a higher excess of diethylzinc led to increased conversion without loss of $e e$ and no significant formation of side products (entry 2). On the other hand, increasing the reaction temperature to $20^{\circ} \mathrm{C}$ led to an unacceptable decrease in enantioselectivity (entry 3). A further improvement of the performance of the system could be achieved by setting the reaction temperature to $10{ }^{\circ} \mathrm{C}$ (entries 4-6). Working at this temperature and adjusting the aldehyde:boroxin:diethylzinc ratio to 1:0.6:2.5 the product was obtained in $83 \%$ ee, with complete conversion and no significant decrease in yield due to the formation of byproducts (entry 6). It is worth mentioning that, in this way, the flow system could be operative for several hours without any significant degradation of the catalytic activity. For example, after 4 h, $3.2 \mathrm{~g}$ of $(S)$-phenyl(4-tolyl)methanol were obtained $(80 \%$ yield) with $81 \% e e$.

\section{Scope of the continuous flow arylation}

As previously demonstrated for catalyst $\mathbf{1}$, this method can be used for the preparation of diarylmethanols with a wide variety of substituents, regardless of their electronic properties, provided that an adequate combination of aldehyde and arylating agent is chosen [30]. Thus, aryl(phenyl)methanols,

\begin{tabular}{|c|c|c|c|c|c|c|}
\hline Entry & $(\mathrm{PhBO})_{3}$ (equiv) & $\mathrm{ZnEt}_{2}$ (equiv) & $\mathrm{T}\left({ }^{\circ} \mathrm{C}\right)$ & Conv $(\%)^{b}$ & Yield (\%) & ee $(\%)^{c}$ \\
\hline 1 & 0.4 & 1.6 & 0 & 40 & 36 & 76 \\
\hline 2 & 0.4 & 3.0 & 0 & 71 & 59 & 78 \\
\hline 3 & 0.4 & 3.0 & 20 & 99 & 82 & 67 \\
\hline 4 & 0.4 & 2.5 & 10 & 84 & 72 & 81 \\
\hline 5 & 0.5 & 2.7 & 10 & 95 & 83 & 83 \\
\hline 6 & 0.6 & 2.5 & 10 & 99 & 91 & 83 \\
\hline
\end{tabular}

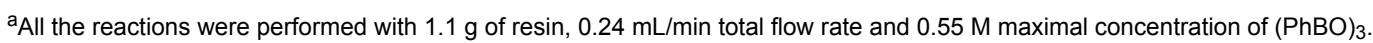

${ }^{b}$ Conversion and yield determined by GC with tridecane as internal standard.

cee determined by HPLC with a chiral column (for details see Supporting Information File 1). 
with the aryl group bearing electron-withdrawing substituents, can be prepared easily by phenylation of the corresponding aldehyde. On the other hand, if a diarylcarbinol has to be prepared where one of the aryl groups bears electron donating substituents, the phenylation of the electron rich benzaldehyde is not efficient, so that the use of an electron rich boroxin in combination with benzaldehyde is preferred (Scheme 5).

We have summarized in Table 3 the results of the continuous flow arylation of a family of aldehydes. This study was done under the set of experimental conditions previously optimized for the phenylation of $p$-tolualdehyde (see Table 2, above), and the results given in the table refer to instant conversion and enantioselectivity after given reaction times.

In all the studied cases tested, except in the phenylation of $\alpha$-methylcinnamaldehyde (entry 5 ), the reaction could be run for some hours without significant decrease in the conversion of the starting aldehydes, thus allowing the preparation of enantioenriched carbinol products in multigram scale. Most attention was devoted to the use of PhZnEt (from triphenylboroxin and diethylzinc) in combination with different aromatic aldehydes (entries 1-4). Among these cases, the best results were obtained with $p$-tolualdehyde (entry 1 ). With $o$-fluorobenzaldehyde (entry 2), $p$-chlorobenzaldehyde (entry 3 ) and 2-naphthaldehyde (entry 4) conversions were excellent over the whole flow experiments ( 3 or $4 \mathrm{~h}$ ), although enantioselectivities were slightly lower [30]. When an $\alpha, \beta$-unsaturated aldehyde, such as $\alpha$-methylcinnamaldehyde was used (entry 5), a fast reaction took initially place, although conversion was observed to slowly decrease after $2 \mathrm{~h}$. Finally, $\left(4-\mathrm{MeOC}_{6} \mathrm{H}_{4}\right) \mathrm{ZnEt}$ [from tri $(p$-methoxyphenyl)boroxin and diethylzinc] could also be used in the continuous flow process with excellent conversion and moderate enantioselectivity (entry 6).

It is interesting to note that, although enantioselectivities were not as high as those obtained with the homogeneous catalyst $\mathbf{1}$ under batch conditions with the same arylating agents [30], or even with the heterogeneous catalyst 2 used under batch conditions with PhZnEt generated from diethylzinc and the very expensive diphenylzinc [22], the addition products could be easily crystallized in order to improve their enantiomeric purities. For instance, phenyl(4-tolyl)methanol could be obtained in pure form, in $76 \%$ yield and $93 \%$ ee after a single crystallization and 4-chlorophenyl(phenyl)methanol in $67 \%$ yield and $86 \%$ ee after the same process.

\section{Conclusion}

In summary, the first single-pass, continuous flow enantioselective arylation of aldehydes has been developed. In this manner, enantioenriched diarylmethanols can be prepared in large scale through a simple and efficient process. The system has been optimized for the use of arylboroxins as an atom economical, cheap and readily available source of aryl groups. The simple procedures required for the purification and enantioenrichment of the resulting carbinols converts this flow process into a convenient alternative for the multigram production of these compounds.

The observed decrease in the enantioselectivity induced by the catalyst in comparison to its homogeneous analogue $\mathbf{1}$, suggests some participation of triethylboroxin in a competing, non-enantioselective catalytic event. In fact, boroxins present adjacent atoms with complementary Lewis base $(\mathrm{O})$ and Lewis acid (B) character that could coordinate the reactant molecules (aldehyde and arylethylzinc) in an arrangement suitable for reaction. In this sense, it is noteworthy that when control experiments were done by using resin 2 under batch conditions with the $\mathrm{Ph}_{2} \mathrm{Zn} / \mathrm{Et}_{2} \mathrm{Zn}$ combination of reagents for the generation of $\mathrm{PhZnEt}$, the observed enantioselectivities were comparable to those recorded with the homogeneous catalyst $\mathbf{1}$. Thus, further improvement of the present continuous flow system could possibly be achieved with the use of alternative sources of the arylating species [33-35].

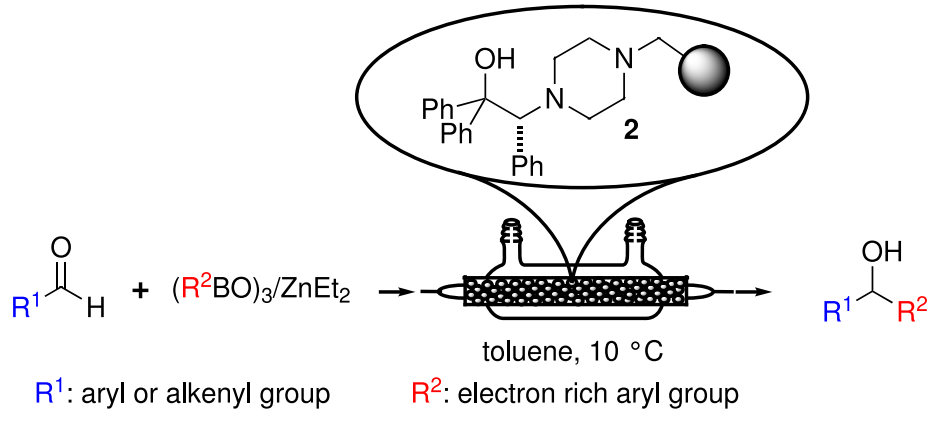

Scheme 5: Continuous flow enantioselective preparation of diarylmethanols. 
Table 3: Substrate scope in the continuous flow arylation of aldehydes. ${ }^{\text {a }}$

\begin{tabular}{|c|c|c|c|c|}
\hline Entry & Product & Time (h) & Conv (\%) & $\%$ ee \\
\hline 1 & & $\begin{array}{l}1 \\
2 \\
3 \\
4 \\
\text { Overall }^{b}\end{array}$ & $\begin{array}{l}99 \\
98 \\
98 \\
98 \\
80^{d}(76)^{e}\end{array}$ & $\begin{array}{l}83 \\
82 \\
81 \\
79 \\
81(93)^{\mathrm{e}}\end{array}$ \\
\hline 2 & & $\begin{array}{l}1 \\
2 \\
3 \\
\text { Overallb }\end{array}$ & $\begin{array}{l}99 \\
99 \\
99 \\
91^{d}\end{array}$ & $\begin{array}{l}58 \\
56 \\
53 \\
55\end{array}$ \\
\hline 3 & & $\begin{array}{l}1 \\
2 \\
3 \\
4 \\
\text { Overall }^{b}\end{array}$ & $\begin{array}{l}99 \\
99 \\
99 \\
99 \\
78^{d}(67)^{e}\end{array}$ & $\begin{array}{l}72 \\
70 \\
67 \\
65 \\
68(86)^{\mathrm{e}}\end{array}$ \\
\hline 4 & & $\begin{array}{l}1 \\
2 \\
3 \\
4 \\
\text { Overall }^{b}\end{array}$ & $\begin{array}{l}>99 \\
>99 \\
>99 \\
>99 \\
93^{d}\end{array}$ & $\begin{array}{l}81 \\
74 \\
70 \\
69 \\
70\end{array}$ \\
\hline 5 & & $\begin{array}{l}1 \\
2 \\
3 \\
\text { Overall }^{b}\end{array}$ & $\begin{array}{l}99^{c} \\
>99^{c} \\
82^{c} \\
82^{d}\end{array}$ & $\begin{array}{l}- \\
- \\
- \\
66\end{array}$ \\
\hline 6 & & $\begin{array}{l}1 \\
2 \\
3 \\
4 \\
\text { Overall }\end{array}$ & $\begin{array}{l}99 \\
>99 \\
>99 \\
97 \\
83^{d}\end{array}$ & $\begin{array}{l}57 \\
60 \\
62 \\
67 \\
63\end{array}$ \\
\hline
\end{tabular}

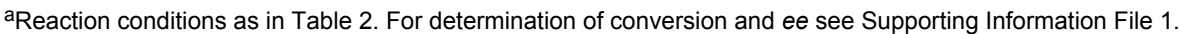

${ }^{b}$ Data for the whole flow experiment.

CDetermined by ${ }^{1} \mathrm{H}$ NMR.

disolated yield.

eAfter a single recrystallization.

\section{Experimental}

\section{General procedure for the arylation of alde- hydes under batch conditions}

A solution of $\mathrm{ZnEt}_{2}(257 \mathrm{mg}, 2.08 \mathrm{mmol})$ in dry toluene $(1 \mathrm{~mL})$ was added via cannula to a suspension of phenylboroxin (104 $\mathrm{mg}, 0.333 \mathrm{mmol})$ in toluene $(1 \mathrm{~mL})$. The mixture was immediately warmed up to $60{ }^{\circ} \mathrm{C}$ in a preheated bath, in a closed system, and stirred in these conditions for $30 \mathrm{~min}$ before it was allowed to cool down to room temperature.

Meanwhile, catalyst $2(f=0.467 \mathrm{mmol} / \mathrm{g}, 180 \mathrm{mg}, 0.083 \mathrm{mmol})$ was swollen with toluene $(2 \mathrm{~mL})$ for $30 \mathrm{~min}$ and then cooled to $0{ }^{\circ} \mathrm{C}$. The $\mathrm{ZnEt}_{2} /(\mathrm{PhBO})_{3}$ mixture was added and the resulting suspension was stirred for further $30 \mathrm{~min}$.

After this time, tolualdehyde (100 mg, $0.83 \mathrm{mmol}$ ) was added and the reaction mixture was stirred at the same temperature for $1 \mathrm{~h}$. Then, a saturated aqueous solution of $\mathrm{NH}_{4} \mathrm{Cl}$ was added to stop the reaction. The resin was removed by filtration and the biphasic mixture was diluted with dichloromethane and separated. The aqueous layer was extracted with dichloromethane and the combined organic layers were washed with aqueous $\mathrm{NaHCO}_{3}$ solution, dried with $\mathrm{Na}_{2} \mathrm{SO}_{4}$, filtered and concentrated under reduced pressure to obtain the product as a yellow oil.

Flash chromatography through silica gel with hexane-ethyl acetate mixtures afforded the pure phenyl(4-tolyl)methanol in pure form as a white solid (119 $\mathrm{mg}, 72 \%$ yield, $89 \%$ ee).

Conversion and GC yield were determined by GC analysis of samples of the organic solution before it was concentrated, with a HP-5 column. Enantiomeric excess was determined by HPLC analysis of the pure product with an AD-H column. Exact conditions for this and other products are given in Supporting Information File 1. 


\section{General procedure for the phenylation of tolu- aldehyde in continuous flow conditions}

The continuous flow system was set up as described in Figure 3. The column was filled with $1.1 \mathrm{~g}$ of resin, and it was swollen with a $0.24 \mathrm{~mL} \cdot \mathrm{min}^{-1}$ flow of dry toluene for $30 \mathrm{~min}$. After that, a $1.1 \mathrm{M}$ solution of the arylating agent, prepared as described above with $(\mathrm{PhBO})_{3}(3.77 \mathrm{~g}, 12.1 \mathrm{mmol})$ and $\mathrm{Et}_{2} \mathrm{Zn}$ $(6.23 \mathrm{~g}, 50.4 \mathrm{mmol})$ in toluene $(33 \mathrm{~mL})$, was connected to one of the pumps, at $0.12 \mathrm{~mL} \cdot \mathrm{min}^{-1}$, while toluene $\left(0.12 \mathrm{~mL} \cdot \mathrm{min}^{-1}\right)$ was kept in the other one, and the column was cooled down to $10{ }^{\circ} \mathrm{C}$. These conditions were kept for a further $1 \mathrm{~h}$, in order to form the amino alcohol-Zn complex. Then, a $0.61 \mathrm{M}$ solution of tolualdehyde (2.42 g, $20.16 \mathrm{mmol})$ in toluene $(33 \mathrm{~mL})$ was connected to the second pump, keeping the same flow.

The product eluting of the column was collected in a flask containing a vigorously stirred aqueous $\mathrm{NH}_{4} \mathrm{Cl}$ solution, in order to stop the reaction.

The reaction progress was monitored by taking samples of approximately $50 \mu \mathrm{L}$ and analyzing them by GC. The samples were treated with aqueous $\mathrm{NH}_{4} \mathrm{Cl}$, extracted with dichloromethane and filtered through $\mathrm{Na}_{2} \mathrm{SO}_{4}$ before they were injected in the GC apparatus. These same samples were analyzed by HPLC in order to determine the ee (see Supporting Information File 1 for further detail).

After $4 \mathrm{~h}$, both reactants were stopped and the system was washed by pumping toluene again for $30 \mathrm{~min}$. The biphasic mixture containing the product was extracted with dichloromethane, washed with aqueous $\mathrm{NaHCO}_{3}$, dried with $\mathrm{Na}_{2} \mathrm{SO}_{4}$ and concentrated under reduced pressure. After flash chromatography on silica gel, $3.2 \mathrm{~g}$ of the product ( $80 \%$ yield) was obtained as a white solid, with $81 \%$ ee. A single crystallization from hexane afforded $2.4 \mathrm{~g}$ ( $76 \%$ yield) with $93 \%$ ee.

\section{Supporting Information}

Supporting information contains GC and HPLC conditions for the analysis of the diarylmethanol products.

\section{Supporting Information File 1}

Conditions for the analysis of the diarylmethanols by GC and HPLC.

[http://www.beilstein-journals.org/bjoc/content/ supplementary/1860-5397-5-56-S1.pdf]

\section{Acknowledgements}

ICIQ foundation is acknowledged for financial support.

\section{References}

1. Noyori, R.; Kitamura, M. Angew. Chem., Int. Ed. Engl. 1991, 30, 49-69. doi:10.1002/anie.199100491

2. Ohkuma, T.; Koizumi, M.; Ikehira, H.; Yokozawa, T.; Noyori, R. Org. Lett. 2000, 2, 659-662. doi:10.1021/ol9904139

3. Corey, E. J.; Helal, C. J. Tetrahedron Lett. 1996, 37, 5675-5678. doi:10.1016/0040-4039(96)01198-7

4. Corey, E. J.; Helal, C. J. Tetrahedron Lett. 1995, 36, 9153-9156. doi:10.1016/0040-4039(95)01961-G

5. Schmidt, F.; Stemmler, R. T.; Rudolph, J.; Bolm, C. Chem. Soc. Rev. 2006, 35, 454-470. doi:10.1039/b600091f

6. Bolm, C.; Hildebrand, J. P.; Muñiz, K.; Hermanns, N. Angew. Chem., Int. Ed. 2001, 40, 3284-3308. doi:10.1002/15213773(20010917)40:18<3284::AID-ANIE3284>3.0.CO;2-U

7. $\mathrm{Pu}, \mathrm{L}$.; Yu, H.-B. Chem. Rev. 2001, 101, 757-824. doi:10.1021/ cr000411y

8. Yus, M.; Ramón, D. J.; Prieto, O. Eur. J. Org. Chem. 2003, 2745-2748. doi:10.1002/ejoc.200300261

9. Jeon, S.-J.; Walsh, P. J. J. Am. Chem. Soc. 2003, 125, 9544-9545. doi:10.1021/ja036302t

10. Hermanns, N.; Dahmen, S.; Bolm, C.; Bräse, S. Angew. Chem., Int. Ed. 2002, 41, 3692-3694. doi:10.1002/15213773(20021004)41:19<3692::AID-ANIE3692>3.0.CO;2-N

11. Bolm, C.; Kesselgruber, M.; Hermanns, N.; Hildebrand, J. P.; Raabe, G. Angew. Chem., Int. Ed. 2001, 40, 1488-1490. doi:10.1002/ 1521-3773(20010417)40:8<1488::AID-ANIE1488>3.0.CO;2-B

12. Bolm, C.; Hermanns, N.; Hildebrand, J. P.; Muñiz, K. Angew. Chem., Int. Ed. 2000, 39, 3465-3467. doi:10.1002/15213773(20001002)39:19<3465::AID-ANIE3465>3.0.CO;2-4

13. Bolm, C.; Muñiz, K. Chem. Commun. 1999, 1295-1296. doi:10.1039/ a903884a

14. Ko, D.-H.; Kim, K. H.; Ha, D.-C. Org. Lett. 2002, 4, 3759-3762. doi:10.1021/ol026761j

15. Huang, W.-S.; Hu, Q.-S.; Pu, L. J. Org. Chem. 1999, 64, 7940-7956. doi:10.1021/jo990992v

16. Solà, L.; Reddy, K. S.; Vidal-Ferran, A.; Moyano, A.; Pericàs, M. A.; Riera, A.; Alvarez-Larena, A.; Piniella, J.-F. J. Org. Chem. 1998, 63, 7078-7082. doi:10.1021/jo981336i

17. García-Delgado, N.; Fontes, M.; Pericàs, M. A.; Riera, A.; Verdaguer, X. Tetrahedron: Asymmetry 2004, 15, 2085-2090. doi:10.1016/j.tetasy.2004.05.026

18. Fontes, M.; Verdaguer, X.; Solà, L.; Pericàs, M. A.; Riera, A. J. Org. Chem. 2004, 69, 2532-2543. doi:10.1021/jo035824o

19. Pericàs, M. A.; Castellnou, D.; Rodríguez, I.; Riera, A.; Solà, L. Adv. Synth. Catal. 2003, 345, 1305-1313. doi:10.1002/ adsc. 200303125

20. Fraile, J. M.; Mayoral, J. A.; Serrano, J.; Pericàs, M. A.; Solà, L.; Castellnou, D. Org. Lett. 2003, 5, 4333-4335. doi:10.1021/ol0355985

21. Castellnou, D.; Solà, L.; Jimeno, C.; Fraile, J. M.; Mayoral, J. A.; Riera, A.; Pericàs, M. A. J. Org. Chem. 2005, 70, 433-438. doi:10.1021/jo048310d

22. Castellnou, D.; Fontes, M.; Jimeno, C.; Font, D.; Solà, L.; Verdaguer, X.; Pericàs, M. A. Tetrahedron 2005, 61, 12111-12120. doi:10.1016/j.tet.2005.07.112

23. Pericàs, M. A.; Herrerías, C. I.; Solà, L. Adv. Synth. Catal. 2008, 350 , 927-932. doi:10.1002/adsc.200800108

24. Schmidt, F.; Rudolph, J.; Bolm, C. Adv. Synth. Catal. 2007, 349, 703-708. doi:10.1002/adsc.200600390

25. Rudolph, J.; Lormann, M.; Bolm, C.; Dahmen, S. Adv. Synth. Catal. 2005, 347, 1361-1368. doi:10.1002/adsc.200505090 
26. Rudolph, J.; Schmidt, F.; Bolm, C. Synthesis 2005, 840-842. doi:10.1055/s-2004-834887

27. Ozçubukçu, S.; Schmidt, F.; Bolm, C. Org. Lett. 2005, 7, 1407-1409. doi:10.1021/ol050242+

28. Rudolph, J.; Hermanns, N.; Bolm, C. J. Org. Chem. 2004, 69, 3997-4000. doi:10.1021/jo0495079

29. Bolm, C.; Rudolph, J. J. Am. Chem. Soc. 2002, 124, 14850-14851. doi:10.1021/ja028518।

30. Jimeno, C.; Sayalero, S.; Fjermestad, T.; Colet, G.; Maseras, F.; Pericàs, M. A. Angew. Chem., Int. Ed. 2008, 47, 1098-1101. doi:10.1002/anie.200703103

31. Chai, Z.; Liu, X.-Y.; Wu, X.-Y.; Zhao, G. Tetrahedron: Asymmetry 2006, 17, 2442-2447. doi:10.1016/j.tetasy.2006.09.004

32. Wu, X.; Liu, X.; Zhao, G. Tetrahedron: Asymmetry 2005, 16 , 2299-2305. doi:10.1016/j.tetasy.2005.06.010

33. Kim, J. G.; Walsh, P. J. Angew. Chem., Int. Ed. 2006, 45, 4175-4178. doi:10.1002/anie.200600741

34. Côté, A.; Charette, A. B. J. Am. Chem. Soc. 2008, 130, 2771-2773. doi:10.1021/ja710864p

35. Muramatsu, Y.; Harada, T. Chem.-Eur. J. 2008, 14, 10560-10563. doi:10.1002/chem.200801612

36. Wiles, C.; Watts, P. Eur. J. Org. Chem. 2008, 1655-1671. doi:10.1002/ ejoc. 200701041

37. Mason, B. P.; Price, K. E.; Steinbacher, J. L.; Bogdan, A. R.; McQuade, D. T. Chem. Rev. 2007, 107, 2300-2318. doi:10.1021/ cr050944c

38. Cozzi, F. Adv. Synth. Catal. 2006, 348, 1367-1390. doi:10.1002/ adsc.200606096

39. Kirschning, A.; Solodenko, W.; Mennecke, K. Chem.-Eur. J. 2006, 12, 5972-5990. doi:10.1002/chem.200600236

40. Saaby, S.; Knudsen, K. R.; Ladlow, M.; Ley, S. V. Chem. Commun 2005, 2909-2911. doi:10.1039/b504854k

41. Baxendale, I. R.; Deeley, J.; Griffiths-Jones, C. M.; Ley, S. V.; Saaby, S.; Tranmer, G. K. Chem. Commun. 2006, 2566-2568. doi:10.1039/b600382f

42. Bogdan, A. R.; Mason, B. P.; Sylvester, K. T.; McQuade, D. T. Angew. Chem., Int. Ed. 2007, 46, 1698-1701. doi:10.1002/ anie. 200603854

43. Smith, C. D.; Baxendale, I. R.; Lanners, S.; Hayward, J. J.; Smith, S. C.; Ley, S. V. Org. Biomol. Chem. 2007, 5, 1559-1561. doi:10.1039/b702995k

44. Nagaki, A.; Takabayashi, N.; Tomida, Y.; Yoshida, J.-i. Beilstein J. Org. Chem. 2009, 5, No. 16. doi:10.3762/bjoc.5.16

45. Bogdan, A.; McQuade, D. T. Beilstein J. Org. Chem. 2009, 5, No. 17. doi:10.3762/bjoc.5.17

46. Yamada, Y. M. A.; Torii, K.; Uozumi, Y. Beilstein J. Org. Chem. 2009, 5, No. 18. doi:10.3762/bjoc.5.18

47. Mennecke, K.; Kirschning, A. Beilstein J. Org. Chem. 2009, 5, No. 21. doi:10.3762/bjoc.5.21

48. Palmieri, A.; Ley, S. V.; Polyzos, A.; Ladlow, M.; Baxendale, I. R. Beilstein J. Org. Chem. 2009, 5, No. 23. doi:10.3762/bjoc.5.23

49. Wiles, C.; Hammond, M. J.; Watts, P. Beilstein J. Org. Chem. 2009, 5, No. 27. doi:10.3762/bjoc.5.27

50. Styring, P.; Parracho, A. I. R. Beilstein J. Org. Chem. 2009, 5, No. 29 doi:10.3762/bjoc.5.29

51. Brandt, J. C.; Wirth, T. Beilstein J. Org. Chem. 2009, 5, No. 30. doi: $10.3762 /$ bjoc.5.30

52. Mak, X. Y.; Laurino, P.; Seeberger, P. H. Beilstein J. Org. Chem. 2009, 5, No. 19. doi:10.3762/bjoc.5.19

For a most recent review.
53. Stephenson, P.; Kondor, B.; Licence, P.; Scovell, K.; Ross, S. K.; Poliakoff, M. Adv. Synth. Catal. 2006, 348, 1605-1610. doi:10.1002/ adsc. 200606172

54. Bonfils, F.; Cazaux, I.; Hodge, P.; Caze, C. Org. Biomol. Chem. 2006, 4, 493-497. doi:10.1039/b515241k

55. Solodenko, W.; Jas, G.; Kunz, U.; Kirschning, A. Synthesis 2007, 583-589. doi:10.1055/s-2007-965877

56. Odedra, A.; Seeberger, P. H. Angew. Chem., Int. Ed. 2009, 48, 2699-2702. doi:10.1002/anie.200804407

57. Popa, D.; Marcos, R.; Sayalero, S.; Vidal-Ferran, A.; Pericàs, M. A. Adv. Synth. Catal. 2009, 351, 1539-1556. doi:10.1002/ adsc. 200900163

58. This epoxide can be routinely prepared at the molar scale in $>99.9 \%$ ee by Jacobsen epoxidation of triphenylethylene and recrystallization from hexane [59].

59. Brandes, B. D.; Jacobsen, E. N. J. Org. Chem. 1994, 59, 4378-4380. doi:10.1021/jo00095a009

\section{License and Terms}

This is an Open Access article under the terms of the Creative Commons Attribution License (http:// creativecommons.org/licenses/by/2.0), which permits unrestricted use, distribution, and reproduction in any medium, provided the original work is properly cited.

The license is subject to the Beilstein Journal of Organic Chemistry terms and conditions: (http://www.beilsteinjournals.org/bjoc)

The definitive version of this article is the electronic one which can be found at: doi:10.3762/bjoc.5.56 